\title{
Management of Reflux Symptoms with Over-the-Counter Proton Pump Inhibitors: Issues and Proposed Guidelines
}

\author{
Sebastian Haag ${ }^{a}$ Jane M. Andrews ${ }^{b}$ Peter H. Katelaris ${ }^{c}$ Judith Gapasin ${ }^{d}$ \\ Jean Paul Galmiche ${ }^{e}$ Richard Hunt ${ }^{f}$ Peter Layer ${ }^{g}$ Peter Malfertheiner ${ }^{h}$ \\ Gerald Holtmann ${ }^{\mathrm{i}}$

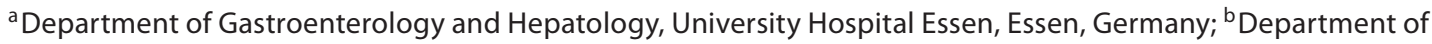 \\ Gastroenterology and Hepatology, Royal Adelaide Hospital and School of Medicine, University of Adelaide, \\ Adelaide, S.A., 'Department of Gastroenterology, Concord Hospital, University of Sydney, Sydney, N.S.W., Australia; \\ dInstitute of Digestive Diseases, St. Luke's Medical Center, Quezon City, Quezon, Philippines; ${ }^{\text {eDepartment of }}$ \\ Gastroenterology and Hepatology, Hotel-Dieu University Hospital, Nantes, France; ${ }^{f}$ Farncombe Family Digestive \\ Disease Research Institute, Division of Gastroenterology, McMaster University Health Science Centre, Hamilton, Ont., \\ Canada; ${ }^{9}$ Department of Gastroenterology and Hepatology, Israelitisches Krankenhaus, Hamburg, h Department of \\ Gastroenterology, Hepatology and Infectious Disease, University Hospital Magdeburg, Magdeburg, 'University of \\ Essen, Executive Board, Essen, Germany; Department of Medicine, University of Adelaide, Adelaide, S.A., Australia
}

\section{Key Words}

Proton pump inhibitors - Gastroesophageal reflux disease · Over-the-counter therapy $\cdot$ Histamine 2 receptor antagonist

\begin{abstract}
Background: Symptoms of gastroesophageal reflux are widely prevalent. There is a continuum between subjects with mild reflux symptoms and those severely affected by gastroesophageal reflux disease (GERD). Both groups may at times access over-the-counter (OTC) therapies. For the purpose of this review, relevant papers, including national and international guidelines were reviewed and recommendations made for appropriate use of OTC proton pump inhibitor (PPI) therapy. Results: PPIs are the gold standard for treatment of reflux symptoms. OTC therapy with histamine ${ }_{2}$ receptor antagonists (H2RAs) also plays a role. For the majority affected by reflux symptoms, effective symptom control is the most important outcome, as only a subgroup requires
\end{abstract}

investigations or interventions. However, patients with alarm features (i.e. troublesome dysphagia, weight loss, predominant upper abdominal pain) are not recommended for OTC therapy and need prompt medical referral. Frequent relapses or failure to adequately respond to OTC therapy are additional triggers for medical assessment. Conclusions: OTC treatment of typical reflux symptoms (acid regurgitation, heartburn) with antacids and H2RAs is now accepted as safe and results in short-term relief of symptoms. There is no evidence of additional risk with OTC PPIs compared to these existing OTC therapies and PPIs are significantly more efficacious.

Copyright $\odot 2009$ S. Karger AG, Basel

This article is based on a workshop that was held in Cairo, Egypt, November 20-22, 2008, and includes papers and guidelines published until February 2009. The meeting was supported by an unrestricted grant from Nycomed.

\section{KARGER}

Fax +41 613061234 E-Mail karger@karger.ch www.karger.com
(C) 2009 S. Karger AG, Basel 0012-2823/09/0804-0226\$26.00/0

Accessible online at: www.karger.com/dig
Prof. Gerald Holtmann, MD, PhD, MBA

University Hospital Essen

Hufeland Strasse 55

DE-45122 Essen (Germany)

Tel. +49 201723 5000, Fax +49 201723 5002, E-Mail gerald.holtmann@uk-essen.de 


\section{Introduction}

Self-medication for symptoms of gastroesophageal reflux (GER; heartburn, acid regurgitation) is very common $[1,2]$, usually with antacids, alginates and histamine $_{2}$ receptor antagonists (H2RAs). As proton pump inhibitors (PPIs) become available for over-the-counter (OTC) use in many countries, there needs to be consideration of how to best use these agents safely and effectively. Additionally, there is a need for guidelines for pharmacy use to assist with safe and effective treatment of reflux symptoms with OTC PPIs. The aim of this article is to review the evidence and the ramifications for OTC use of PPIs in subjects with reflux symptoms. It summarizes the results of a working party involving researchers from Europe, North America, Asia, and Australia.

GER is very common and has a broad spectrum of presentations. The hallmark symptoms are heartburn and acid regurgitation. The distinction between reflux and GER disease (GERD) has been related to the frequency and impact of symptoms. However, only a proportion of sufferers seek medical attention. A large proportion of those not seeking medical attention have self-medicated for many years with antacids, alginates and H2RAs $[1,2]$ as these are available OTC in virtually all countries. Selfmedication with H2RAs was initially controversial, however it is now generally accepted that such self-medication is safe [3]. PPIs are currently accepted as the treatment of choice for reflux symptoms as they provide superior symptom relief to H2RAs [4] and better healing of esophagitis when present $[4,5]$. In addition to having an excellent safety profile, PPIs are now becoming available OTC in many countries [6], and it is inevitable that their availability will increase. Hence there is need for the current review and recommendations.

There are many comprehensive written guidelines for the management of GERD directed at the medical community [7-15], but these are not for pharmacy use, where much reflux treatment is obtained. This document aims to address the appropriate OTC use of PPIs and limitations that should apply when reflux sufferers initially seek to self-medicate prior to consulting a physician. In many countries, GERD management guidelines predate the availability of OTC PPIs and thus do not specifically address this issue. In this context, the pharmacist is effectively rendered the 'gatekeeper', and plays a vital role in ensuring the best use of OTC PPIs. Importantly, this should be seen as a dual opportunity to provide the most effective therapy for those with typical reflux symptoms who are not currently receiving medical care and also to promptly identify those subjects unsuitable for OTC therapy who should be referred for medical assessment.

\section{Gastroesophageal Reflux}

\section{Definitions}

Gastroesophageal reflux (GER) is the movement of gastric contents (acidic fluid) into the esophagus. Often this results in symptoms, most commonly and most typically heartburn or acid regurgitation [5-13]. Recent opinion defines GER as a disease (GERD) when either the sufferer considers symptoms troublesome and/or GER results in complications [16]. Therefore, in practice, the distinction between reflux symptoms and GERD is usually related to the frequency and impact of symptoms on quality of life. However, there is a continuum between those with 'reflux symptoms' and those with 'reflux disease' and both groups ultimately may consume OTC therapies.

\section{Prevalence and Spectrum}

Reflux symptoms are very common. Population-based studies show that a considerable proportion of the population suffers from heartburn once to several times per day. The rates in Europe range between $10-20 \%$ and in the USA from $20-28 \%$ [17-20], while the prevalence in Asia is lower but appears to be rising in some countries $[21,22]$. Overall, GER symptoms (GERS) and GERD are among the most common disorders and consume considerable healthcare resources [23].

There is a spectrum of severity of reflux symptoms which relates to the intensity, duration and frequency of individual episodes. On one end of the spectrum are those with severe daily symptoms, whilst at the milder end symptoms are intermittent and periodic [24, 25]. Surveys show that up to $30 \%$ of the adult population may suffer from symptoms, but that these wax and wane $[18$, 26].

Thus, the management of reflux symptoms necessarily varies according to individual severity and frequency and therefore no single treatment strategy is appropriate for all sufferers. The approach to management needs to be tailored and should take into account the frequency, severity and duration of symptoms and the impact on an individual. 


\section{Diagnosis and Diagnostic Methods}

As GER is very common, well recognized and frequently present in individuals for many years prior to medical consultation, it can usually be confidently diagnosed at the initial office visit in those with typical symptoms and treatment started without formal investigation(s) $[27,28]$. A formal diagnostic workup, beyond history and clinical examination, is not required in the vast majority of reflux sufferers. This is consistent with usual clinical practice worldwide and is in accordance with many international guidelines [7-15].

However, where alarm features are present, a diagnostic workup is required, as when the diagnosis is uncertain. Thus the goal of a diagnostic workup in those with reflux symptoms is not simply to confirm the diagnosis but to reasonably exclude other diagnoses (e.g. peptic ulcer disease, upper gastrointestinal malignancy, etc.) or to identify complications of GERD such as stricture or Barrett's esophagus which may alter subsequent therapeutic management.

\section{Role and Relevant Possible Findings of Endoscopy in} the Presence of Reflux Symptoms

In the past, the assessment of reflux symptoms was oriented particularly towards the finding of mucosal lesions. In this paradigm, diagnostic methods such as endoscopy (or X-rays) were central. Today this is viewed differently, as we know that symptoms and lesions correlate poorly [29], and that $\sim 70 \%$ of those with reflux symptoms will have endoscopy-negative/non-erosive disease [30]. Moreover, regarding management, the recent Montreal consensus document states that '... the approach is independent of the findings of the endoscopy....' [16].

Whilst, upper gastrointestinal endoscopy (UGIE) is still considered the most important diagnostic procedure in patients with reflux symptoms, there is no evidence that routine UGIE in those with reflux symptoms has any influence on the incidence of finding a carcinoma [31, 32]. In one study of 7,159 patients presenting with new onset reflux symptoms, 805 were selected by the general practitioner (GP), presumably due to concern about the diagnosis, for referral for UGIE. The rate of finding either adenocarcinoma or Barrett's was extremely low: $<1 \%$ for each [33]. Moreover, another study of 300 patients over 65 years of age presenting for screening colonoscopy, who additionally all had an UGIE [34] found that the detection rate of Barrett's esophagus was unrelated to any previously reported symptoms (i.e. acid regurgitation or heartburn) of GERD. Thus, in older people, the yield of UGIE for Barrett's esophagus was similar in asymptomatic subjects to those with reflux symptoms. Similar results have been reported by the Kalixandra study group [35]. They investigated a random sample of an adult population $(n=3,000)$ for gastrointestinal symptoms and another random sample $(n=1,000)$ underwent UGIE. GERS were reported by $40.0 \%$ and erosive esophagitis (EE) was found in $15.5 \%$ of the population that had undergone endoscopy. Only $24.5 \%$ of those with GERS had EE while $36.8 \%$ of those with EE reported no GERS [35]. The overall prevalence of peptic ulcers in this population sample was $4.1 \%$. Interestingly, 6 of 20 (30\%) patients with gastric ulcer and 2 of 21 (9.5\%) patients with duodenal ulcer were asymptomatic. Thus, even peptic ulcer disease often coexists with atypical symptoms or no symptoms at all [36].

The situation is similar in those with predominantly epigastric/upper abdominal complaints. Epigastric pain/ discomfort is very common and whilst potentially lifethreatening diseases may present similarly, they are rare compared to functional dyspepsia and reflux. Therefore, it is generally accepted that UGIE is not needed routinely in those with a clinical diagnosis of functional dyspepsia [37]. Rather, empirical symptom-directed therapy is recommended. Furthermore, even if epigastric symptoms are due to malignancy, it is generally already at an advanced stage [38], and thus UGIE will offer no therapeutic advantage. Furthermore, as a lack of prompt and complete response to empirical reflux therapy is recommended as an indication forfurther referraland/or investigation, the use of initial empirical therapy will only result in a short delay in the confirmation of the diagnosis (days to weeks). This timeframe will not influence the prognosis in the case of an advanced neoplasm [39]. Concerns about Helicobacter pylori-related disease in this context can be dealt with by a test and treat approach in primary care, and this, too, has been shown to reduce the need for UGIE [40].

Wo et al. [41] recently investigated the clinical impact of endoscopy in 206 patients with a clinical diagnosis of reflux disease referred for UGIE. They divided them into those with alarm symptoms $(n=124)$ compared to those with persistent heartburn despite therapy $(\mathrm{n}=82)$. Following endoscopy, medical treatment was changed in only $5 \%$ of patients, whilst other changes (e.g. dilatation of stricture, enrollment in surveillance program, etc.) in management were also made. UGIE had a greater clinical impact on decision making in male patients with alarm symptoms in this study, so the authors concluded that 
this was the group most likely to benefit from UGIE [41].

Some proponents recommend UGIE, not for diagnosis, but for prognosis in those with reflux symptoms. They argue that, as chronic reflux disease is a risk factor for the development of Barrett's esophagus, Barrett's dysplasia and esophageal carcinoma, patients with reflux symptoms should consider having a one-off endoscopy to assess for these lesions [38] and, if negative, to provide reassurance to the patient. However, as noted above, Barrett's esophagus can equally occur without reflux symptoms [42]. Moreover, even with reflux symptoms, only $1-10 \%$ of patients have Barrett's esophagus $[43,44]$ and fewer than $1 \%$ of those with Barrett's have significant epithelial dysplasia which would require routine monitoring and/or further treatment $[45,46]$. Arguing further against the ability to target appropriate patients for endoscopy, a recent study concluded that Barrett's esophagus and complications such as dysplasia and esophageal adenocarcinoma occur particularly in patients who do not present with typical reflux symptoms such as heartburn and acid reflux [38].

\section{Risks of Endoscopic Evaluation}

Endoscopy is not risk free. It is estimated that there is one complication per 1,000 interventions and between 0.5 and 3 deaths per 10,000 examinations [47]. Whilst these rates appear low, they are proportionally much more important than the potential risk of any delay in making an alternative diagnosis in a patient with typical reflux symptoms [48]. One should also consider that these published complication rates came from highly specialized centers with presumably below-average complication rates and adverse outcomes may be greater in other endoscopic practice settings.

\section{Does Prior Therapy Affect Endoscopic Utility?}

Some argue that previous empirical treatment may limit the diagnostic utility of a subsequent endoscopy [49]. However, it is not important for an individual patient's prognosis whether or not there is evidence of $\mathrm{EE}$ (that might have healed or have been down staged after a short time on therapy), as it is known that symptoms and endoscopic findings correlate poorly in reflux sufferers [29]. Moreover, Barrett's metaplasia is easier to diagnose in an intact/healed mucosa (i.e. after antisecretory treatment has healed mucosal lesions and decreased inflammation) when differentiation between acute-inflammatory (pseudo-) metaplastic mucosal changes and dysplasia is easier. It may reduce the accuracy of biopsy based tests for $H$. pylori infection, but if required, this can be overcome by ceasing PPIs for a short time prior to endoscopy. Thus, it cannot be argued that prior antisecretory treatment impairs the utility of UGIE.

\section{Other Diagnostic Modalities}

Other diagnostic methods used in those with reflux symptoms include esophageal manometry, $\mathrm{pH}$ studies, barium studies and multi-channel intraluminal impedance monitoring. These are beyond the scope of this article, as they are generally only available in tertiary specialist care centers. The role of these specialized tests in those with (suspected) reflux symptoms is dealt with in other recent reviews [7-15].

In summary, a diagnostic workup and specifically, UGIE, is not considered necessary before initiating antisecretory treatment in someone with typical reflux symptoms (heartburn, acid regurgitation) and no alarm features [50]. Many authors now even question the need for routine UGIE in patients with ongoing symptoms of reflux disease [32] because of the difficulty in demonstrating that it improves outcomes or yields higher detection rates than age- or gender-based screening. Therefore, logically, there is no additional risk in more effective short-term antisecretory therapy being made available OTC for typical reflux symptoms.

\section{Role of Over-the-Counter Treatment}

As reviewed above, patients with mild and uncomplicated symptoms of heartburn and/or regurgitation do not need to be investigated prior to initiating therapy $[7-11,13]$. At present, these individuals frequently seek OTC therapy and will either use OTC antacids, alginates or H2RAs. As PPIs are more effective than these treatments they represent an ideal class of drug for use as OTC reflux therapy for reflux symptoms. Potential users would include those with typical symptoms already using less effective OTC therapy without satisfactory control and treatment-naïve reflux sufferers seeking initial OTC therapy. The ideal subjects appropriate for OTC PPI therapy are those presenting with typical symptoms of heartburn and/or acid regurgitation as their predominant or main complaint. Patients with severe, frequent or troublesome symptoms and those with symptoms of long duration may derive greater benefit from regular/long-term PPI therapy and should be advised to see their doctor to discuss this. One of the challenges with OTC PPI, paradoxically, is to ensure that 
patients who need regular prescription therapy are not under treated.

\section{Ways to Discontinue Therapy Suitable for OTC}

\section{Delivery}

PPIs may be used effectively for mild reflux with various treatment strategies. On-demand or self-directed therapy has been shown to be effective as judged by a patient's willingness to continue and satisfaction with this mode of therapy [51]. Subjects take a dose of medication at the onset of symptoms and discontinue when symptoms are relieved. Clinical experience informs us that many patients determine this as their preferred mode of therapy regardless of medical advice. This is despite the recurrence of symptoms being a prerequisite for reintroduction of therapy. In general, the majority of studies demonstrate a substantial proportion of patients with relief of symptoms after 2 (to 4) weeks of treatment [4].

An alternative mode of therapy for milder disease is intermittent treatment, whereby a sufferer is directed to take a predetermined short-course (typically 2 weeks) of therapy when symptoms recur [52]. Moreover, given what is known about medication compliance in general, it is unlikely that many patients outside clinical trials take their medications as directed more than $50 \%$ of the time. The value of either the on-demand or intermittent strategy is that medication use, and therefore costs, are minimized. Patients are often happy not to be on continuous therapy and indeed, as a large proportion of patients do not relapse or relapse only infrequently, unnecessary prolonged treatment is avoided. Studies show that while up to $30 \%$ of patients will not relapse after a short course of PPI therapy [53] other studies report that more than 50\% of patients with non-erosive reflux disease will relapse within 6 months without continuous therapy [54]. OTC therapy will therefore play a beneficial role as a 'filter' for patients who need to progress to more intense, i.e. more regular, prescription therapy.

\section{Benefits of OTC Approach, Economic Considerations}

The main costs arising from medical care of reflux are UGIE- and medication-related. OTC therapy will effectively be 'on-demand' or 'intermittent' therapy and may lead to decreased consultations and medication costs with acceptable symptom control in most subjects. OTC PPI is also likely to decrease the number needing UGIE, as many will respond quickly and completely to OTC PPI therapy, and thus will not present for further evaluation.
A recent randomized study [55] showed no disadvantage to initiating empirical treatment with a PPI compared to performing prompt endoscopy in subjects with typical reflux symptoms without alarm features. In addition, the empirical PPI therapy strategy was more cost-effective.

\section{Potential or Perceived Hazards}

The two main concerns with OTC PPI and other therapies are the possibility of misdiagnoses or the undertreatment of patients with severe GERD who require supervised medical care rather than OTC therapy.

In practical terms, the main differential diagnoses that are important to make are those which require different therapy or prompt attention. In practice these are cardiovascular disease, upper gut carcinomas, and peptic ulcer disease.

It is usually quite straightforward to make a diagnosis of GER when a patient presents with the cardinal symptoms of heartburn and acid regurgitation. However, if a patient presents with chest pain, the possibility of cardiac disease must be considered. As the dispenser of OTC therapy will not be a doctor, presentation with chest pain should be considered a trigger for referral and medical assessment and such subjects are not appropriate candidates for any OTC therapy for GER until after such an assessment, regardless of whether it is PPI, H2RA or antacids/alginates.

The risk of missing esophageal and gastric cancer in patients with typical symptoms of GER without alarm features is low. Of note, in a large survey of patients ( $\mathrm{n}=$ $7,159)$ with recent onset GER recorded in the British General Practice database, even amongst the $11 \%$ referred for endoscopy by their GPs, the finding of cancer was rare $(<0.4 \%)$ [33]. This is particularly reassuring as these $11 \%$ presumably already had features that concerned the GP sufficiently to refer them. In addition, it is known that most reflux sufferers have had their symptoms for many years and commonly have used other OTC therapy for quite some time. Patients with alarm features do need prompt referral for medical attention but even in this group the yield of malignancy is low [35].

Peptic ulcer disease is a serious benign condition that is usually associated with $H$. pylori infection and/or nonsteroidal anti-inflammatory drugs. When due to $H$. $p y$ lori, ulcer disease usually runs a relapsing and remitting course. Successful eradication of the infection, usually with a PPI combined with two antibiotics for 7-10 days, 


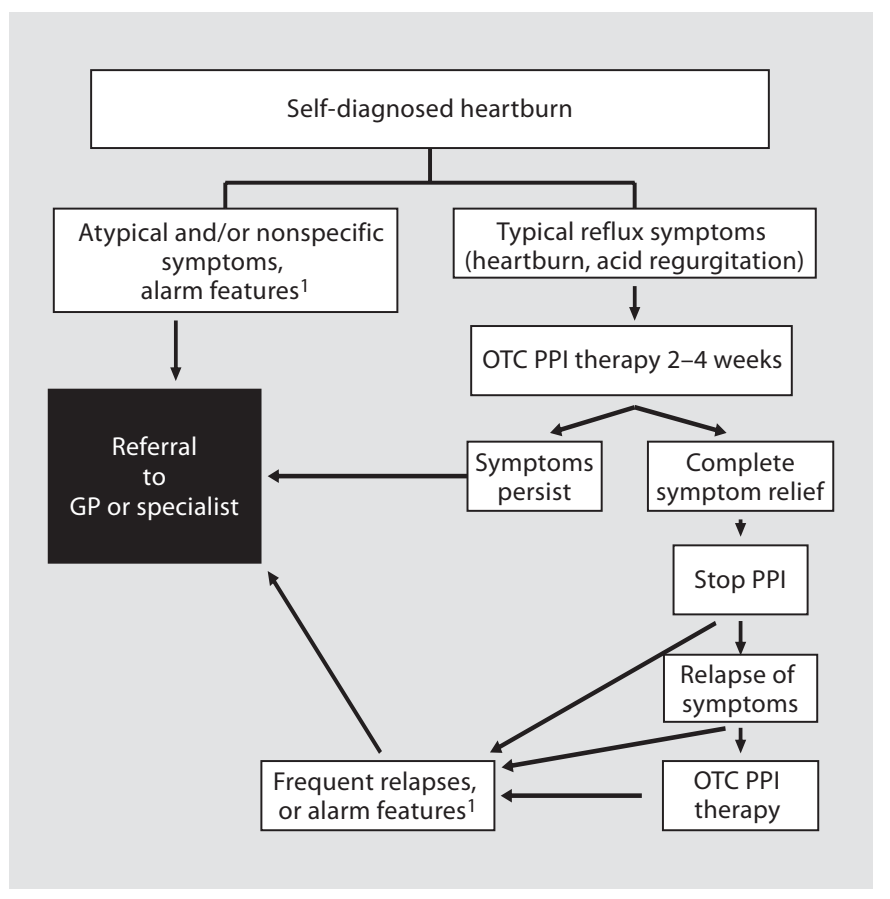

Fig. 1. Algorithm for pharmacy-based management of typical reflux symptoms (heartburn and/or acid regurgitation). PPI = Proton pump inhibitor. ${ }^{1}$ See table 1 .

cures the disease by not only healing current ulcers but also by preventing relapse. Symptoms of ulcer disease overlap with reflux symptoms and can be hard to reliably distinguish in practice. A brief trial of OTC treatment may provide short-term symptom relief for ulcer sufferers but will leave them exposed to the ongoing risk of ulcer relapse and complications including perforation and bleeding. Restricting OTC PPI to sufferers with typical reflux symptoms of heartburn and acid regurgitation, whilst excluding those with predominant epigastric symptoms, largely avoids these risks. Advising referral for frequent OTC users is a further safeguard. Subjects on non-steroidal anti-inflammatory drugs who experience upper gut symptoms including reflux, should be directed to promptly consult their doctor about this.

OTC PPI is not intended as a substitute for medical management and regular treatment in those with severe reflux disease or significant intercurrent medical issues, and such subjects should be identified early and referred [7-15]. This includes patients with very frequent and/or severe symptoms, those with significant comorbidities or those using a number of prescription medications which should be monitored by a physician. The risk of undertreatment exposes those who have severe erosive GERD
Table 1. Referral triggers (atypical, severe symptoms or alarm symptoms) which indicate that medical assessment is warranted

\section{Alarm symptoms \\ - Weight loss, unintentional \\ - Hematemesis (vomiting of blood) \\ - Melena (black feces/blood in stool) \\ - Dysphagia (difficulty swallowing) \\ - Odynophagia (painful swallowing) \\ - Severe symptoms}

\section{Atypical and/or unspecific symptoms}

- Chest pain

- Predominant epigastric pain

- Belching

- Hoarseness

- Sore throat

- Cough

Risk factors, other

- Age $>40$ years in areas with high prevalence of gastric cancer (otherwise $>50-55$ years)

- New onset symptoms in subjects $>45$ years

- Family history of gastric and/or esophageal cancer

- Chronic non-steroidal anti-inflammatory drug use

These referral triggers are independent of the individual firstline treatment approach.

to inadequate symptom relief and the risk of complications such as strictures. These patients need to be identified early so they can be referred early for medical assessment.

Whilst there is some concern that long-term PPI therapy is associated with an increase in pneumonia and gastrointestinal infections $[56,57]$, this is unlikely to be clinically relevant with short-term OTC use of PPIs, as treatment courses should be restricted to 14 days or less.

\section{When and Whom to Refer}

Individuals who are not suitable for initial OTC PPIs should be redirected promptly for medical assessment when they first present to a pharmacy requesting OTC therapy. Those unsuitable for initial OTC PPI include the following.

(1) Sufferers in whom the diagnosis is uncertain, these include:

- Patients who do not have predominant heartburn and/ or acid regurgitation

- Those with chest pain as a predominant symptom

- Those with predominant epigastric symptoms 
(2) Sufferers with alarm symptoms which include:

- Unintended weight loss

- Troublesome dysphagia

- Vomiting

(3) Those with significant comorbidities including those on multiple other therapies who require medical supervision of their overall management.

(4) Sufferers with symptoms that do not sufficiently respond after 2-4 weeks of treatment with a PPI.

After initially accessing OTC PPIs, it is likely some sufferers will present to their pharmacy seeking further OTC therapy. This provides an additional opportunity to ensure these agents are used appropriately. Further OTC PPI should not be supplied:

(1) to anyone who did not experience complete or satisfactory heartburn relief from up to 2 weeks of initial OTC PPI therapy

(2) frequently - as those requiring frequent therapy should be redirected for consideration of continuous prescription therapy.

Table 1 gives a summary of the above referral triggers. An algorithm for pharmacists practice is given in figure 1.

\section{Conclusion}

GER is widely prevalent in the community and the cardinal symptoms of heartburn and acid regurgitation are well recognized by patients. The emerging availability of PPIs in the OTC setting provides an opportunity to improve the quality of care of reflux sufferers who may currently be untreated or under-treated.

PPIs are the gold standard for reflux symptom control. They give a rapid response in a high proportion of subjects at routine doses with a very favorable safety profile.
Ideally with the assistance of a pharmacist, AND clear information provided with the medication, OTC PPIs can be restricted to appropriate consumers. With brief treatment courses provided, there is the opportunity to promptly reassess those who do not respond and refer for medical management.

It is not anticipated that OTC PPIs, used in this recommended fashion, will lead to any greater problems than with the current OTC use of less effective agents.

\section{Conflicts of Interest}

Sebastian Haag has received research support, speaker's fees or travel support from Axcan, Bayer Schering Pharma, Essex Pharma, Fresenius Medical Care, Gilead Sciences, and $\mathrm{Ny}-$ comed.

Jane M. Andrews has received research support, speaker's fees, travel support or honoraria from Abbott, AstraZeneca, Ferring, Fresenius Kabi, J\&J, Nycomed, Orphan, Pharmatel, and ScheringPlough.

Peter H. Katelaris has received speaker's fees and honoraria from AstraZeneca, Jansen-Cilag, and Nycomed.

Judith Gapasin has received speaker's fees and travel support from Nycomed.

Jean Paul Galmiche has received research support and consultant fees from AstraZeneca, Given Imaging, Movetis, and Solvay.

Richard Hunt has been a consultant and/or speaker and/or investigator with Alevium, AstraZeneca, Nycomed, Steba Biotech, and Takeda.

Peter Layer has received research support and consulting fees from Abbott, Axcan, Falk, Norgine, Novartis, Nycomed, and Solvay.

Peter Malfertheiner has received research support and consulting fees from Abbott, AstraZeneca, Bayer Schering Pharma, Novartis, and Nycomed.

Gerald Holtmann has received research support, speaker's fees, travel support or honoraria from Abbott, Ardeypharm, AstraZeneca, Bayer, J\&J, Nycomed, and Steigerwald.

\section{References}

1 Furu K, Straume B: Use of antacids in a general population: the impact of health-related variables, lifestyle and sociodemographic characteristics. J Clin Epidemiol 1999;52: 509-516.

-2 Earnest D, Robinson M, Rodriguez-Stanley S, Ciociola AA, Jaffe P, Silver MT, Kleoudis CS, Murdock RH: Managing heartburn at the 'base' of the GERD 'iceberg': effervescent ranitidine $150 \mathrm{mg}$ b.d. provides faster and better heartburn relief than antacids. Aliment Pharmacol Ther 2000;14:911-918.
- 3 Tytgat GN, McColl K, Tack J, Holtmann G, Hunt RH, Malfertheiner P, Hungin AP, Batchelor HK: New algorithm for the treatment of gastro-oesophageal reflux disease. Aliment Pharmacol Ther 2008;27:249-256.

4 Khan M, Santana J, Donnellan C, Preston C, Moayyedi P: Medical treatments in the short term management of reflux oesophagitis. Cochrane Database Syst Rev 2007;2: CD003244.
5 Chiba N, De Gara CJ, Wilkinson JM, Hunt RH: Speed of healing and symptom relief in grade II to IV gastroesophageal reflux disease: a meta-analysis. Gastroenterology 1997;112:1798-1810.

6 van Pinxteren B, Numans ME, Bonis PA, Lau J: Short-term treatment with proton pump inhibitors, H2-receptor antagonists and prokinetics for gastro-oesophageal reflux disease-like symptoms and endoscopy negative reflux disease. Cochrane Database Syst Rev 2006;3:CD002095. 
7 Fock KM, Talley NJ, Fass R, Goh KL, Katelaris P, Hunt R, Hongo M, Ang TL, Holtmann G, Nandurkar S, Lin SR, Wong BC, Chan FK, Rani AA, Bak YT, Sollano J, Ho KY, Manatsathit S: Asia-Pacific consensus on the management of gastroesophageal reflux disease: update. J Gastroenterol Hepatol 2008;23:8-22.

8 DeVault KR, Castell DO: Guidelines for the diagnosis and treatment of gastroesophageal reflux disease. Practice Parameters Committee of the American College of Gastroenterology. Arch Intern Med 1995;155:21652173.

9 Armstrong D, Marshall JK, Chiba N, Enns R, Fallone CA, Fass R, Hollingworth R, Hunt RH, Kahrilas PJ, Mayrand S, Moayyedi P, Paterson WG, Sadowski D, van Zanten SJ: Canadian Consensus Conference on the management of gastroesophageal reflux disease in adults - update 2004. Can J Gastroenterol 2005;19:15-35.

10 Beck IT, Champion MC, Lemire S, Thomson $\mathrm{AB}$, Anvari M, Armstrong D, Bailey RJ, Barkun AN, Boivin M, Bursey RF, Chaun H, Chiba N, Cockeram AW, Connon JJ, Da Costa LR, Faloon TR, Fedorak RN, Gillies RR, Goeree R, Hunt RH, Inculet RI, Klein A, Leddin DJ, Love JR, Worobetz LJ: The Second Canadian Consensus Conference on the Management of Patients with Gastroesophageal Reflux Disease. Can J Gastroenterol 1997;11(suppl B):7B-20B.

- 11 Moraes-Filho J, Cecconello I, Gama-Rodrigues J, Castro L, Henry MA, Meneghelli UG, Quigley E: Brazilian consensus on gastroesophageal reflux disease: proposals for assessment, classification, and management. Am J Gastroenterol 2002;97:241-248.

-12 Koop H, Schepp W, Muller-Lissner S, Madisch A, Micklefield G, Messmann H, Fuchs $\mathrm{KH}$, Hotz J: Consensus conference of the DGVS on gastroesophageal reflux (in German). Z Gastroenterol 2005;43:163-164.

$\checkmark 13$ Katelaris P, Holloway R, Talley N, Gotley D, Williams S, Dent J: Gastro-oesophageal reflux disease in adults: guidelines for clinicians. J Gastroenterol Hepatol 2002;17:825833.

14 Guidelines for surgical treatment of gastroesophageal reflux disease (GERD). Society of American Gastrointestinal Endoscopic Surgeons (SAGES). Surg Endosc 1998;12:186188.

15 The role of endoscopy in the management of GERD: guidelines for clinical application. From the ASGE. American Society for Gastrointestinal Endoscopy. Gastrointest Endosc 1999;49:834-835.

16 Vakil N, van Zanten SV, Kahrilas P, Dent J, Jones R: The Montreal definition and classification of gastroesophageal reflux disease: a global evidence-based consensus. Am J Gastroenterol 2006;101:1900-1920.
17 Nandurkar S, Talley NJ: Epidemiology and natural history of reflux disease. Baillieres Best Pract Res Clin Gastroenterol 2000;14: 743-757.

18 Dent J, El Serag HB, Wallander MA, Johansson S: Epidemiology of gastro-oesophageal reflux disease: a systematic review. Gut 2005; 54:710-717.

19 Louis E, DeLooze D, Deprez P, Hiele M, Urbain D, Pelckmans P, Deviere J, Deltenre M: Heartburn in Belgium: prevalence, impact on daily life, and utilization of medical resources. Eur J Gastroenterol Hepatol 2002; 14:279-284.

20 Bretagne JF, Richard-Molard B, Honnorat C, Caekaert A, Barthelemy P: Gastroesophageal reflux in the French general population: national survey of 8000 adults. Presse Méd 2006;35:23-31.

21 Goh KL, Chang CS, Fock KM, Ke M, Park HJ, Lam SK: Gastro-oesophageal reflux disease in Asia. J Gastroenterol Hepatol 2000; 15:230-238.

22 Wong BC, Kinoshita Y: Systematic review on epidemiology of gastroesophageal reflux disease in Asia. Clin Gastroenterol Hepatol 2006;4:398-407.

23 Malfertheiner P, Hallerback B: Clinical manifestations and complications of gastroesophageal reflux disease (GERD). Int J Clin Pract 2005;59:346-355.

24 Bolling-Sternevald E, Aro P, Ronkainen J, Storskrubb T, Talley NJ, Junghard O, Agreus L: Do gastrointestinal symptoms fluctuate in the short-term perspective? The Kalixanda study. Dig Dis 2008;26:256-263.

25 Ronkainen J, Aro P, Storskrubb T, Johansson SE, Lind T, Bolling-Sternevald E, Graffner H, Vieth M, Stolte M, Engstrand L, Talley NJ, Agreus L: High prevalence of gastroesophageal reflux symptoms and esophagitis with or without symptoms in the general adult Swedish population: a Kalixanda study report. Scand J Gastroenterol 2005;40:275285.

-26 El Serag HB: Time trends of gastroesophageal reflux disease: a systematic review. Clin Gastroenterol Hepatol 2007;5:17-26.

-27 Klauser AG, Schindlbeck NE, Müller-Lissner SA: Symptoms in gastro-oesophageal reflux disease. Lancet 1990;i:205-208.

28 Kahrilas PJ, Shaheen NJ, Vaezi MF, Hiltz SW, Black E, Modlin IM, Johnson SP, Allen J, Brill JV: American Gastroenterological Association Medical Position Statement on the management of gastroesophageal reflux disease. Gastroenterology 2008;135:1383-1391.

29 Fennerty MB, Johnson DA: Heartburn severity does not predict disease severity in patients with erosive esophagitis. MedGenMed 2006;8:6.

30 Labenz J, Jaspersen D, Kulig M, Leodolter A, Lind T, Meyer-Sabellek W, Stolte M, Vieth M, Willich S, Malfertheiner P: Risk factors for erosive esophagitis: a multivariate analysis based on the ProGERD study initiative. Am J Gastroenterol 2004;99:1652-1656.
31 Pisegna J, Holtmann G, Howden CW, Katelaris $\mathrm{PH}$, Sharma P, Spechler S, Triadafilopoulos G, Tytgat G: Review article: oesophageal complications and consequences of persistent gastro-oesophageal reflux disease. Aliment Pharmacol Ther 2004;20(suppl 9):47-56.

32 Shaheen N, Ransohoff DF: Gastroesophageal reflux, Barrett esophagus, and esophageal cancer: scientific review. JAMA 2002;287: 1972-1981.

>33 Ruigomez A, Rodriguez LA, Wallander MA, Johansson S, Dent J: Endoscopic findings in a cohort of newly diagnosed gastroesophageal reflux disease patients registered in a UK primary care database. Dis Esophagus 2008;21:251-256.

>34 Ward EM, Wolfsen HC, Achem SR, Loeb DS, Krishna M, Hemminger LL, DeVault KR: Barrett's esophagus is common in older men and women undergoing screening colonoscopy regardless of reflux symptoms. Am J Gastroenterol 2006;101:12-17.

-35 Ronkainen J, Aro P, Storskrubb T, Johansson SE, Lind T, Bolling-Sternevald E, Graffner H, Vieth M, Stolte M, Engstrand L, Talley NJ, Agreus L: High prevalence of gastroesophageal reflux symptoms and esophagitis with or without symptoms in the general adult Swedish population: a Kalixanda study report. Scand J Gastroenterol 2005;40:275285.

36 Aro P, Storskrubb T, Ronkainen J, BollingSternevald E, Engstrand L, Vieth M, Stolte M, Talley NJ, Agreus L: Peptic ulcer disease in a general adult population - the Kalixanda study: a random population-based study. Am J Epidemiol 2006;163:1025-1034.

$>37$ Thomson AB, Barkun AN, Armstrong D, Chiba N, White RJ, Daniels S, Escobedo S, Chakraborty B, Sinclair P, van Zanten SJ: The prevalence of clinically significant endoscopic findings in primary care patients with uninvestigated dyspepsia: the Canadian Adult Dyspepsia Empiric Treatment Prompt Endoscopy (CADET-PE) study. Aliment Pharmacol Ther 2003;17:1481-1491.

- 38 Fan X, Snyder N: Prevalence of Barrett's esophagus in patients with or without GERD symptoms: role of race, age, and gender. Dig Dis Sci 2009;54:572-577.

39 Talley NJ, Silverstein MD, Agreus L, Nyren O, Sonnenberg A, Holtmann G: AGA technical review: evaluation of dyspepsia. American Gastroenterological Association. Gastroenterology 1998;114:582-595.

$\checkmark 40$ Malfertheiner P, Megraud F, O'Morain C, Bazzoli F, El Omar E, Graham D, Hunt R, Rokkas T, Vakil N, Kuipers EJ: Current concepts in the management of Helicobacter $p y$ lori infection: the Maastricht III Consensus Report. Gut 2007;56:772-781. 
41 Wo JM, Mendez C, Harrell S, Joubran R, Bressoud PF, McKinney WP: Clinical impact of upper endoscopy in the management of patients with gastroesophageal reflux disease. Am J Gastroenterol 2004;99:23112316.

42 Ronkainen J, Aro P, Storskrubb T, Johansson SE, Lind T, Bolling-Sternevald E, Graffner H, Vieth M, Stolte M, Engstrand L, Talley NJ, Agreus L: High prevalence of gastroesophageal reflux symptoms and esophagitis with or without symptoms in the general adult Swedish population: a Kalixanda study report. Scand J Gastroenterol 2005;40:275285.

43 Reid BJ, Weinstein WM: Barrett's esophagus and adenocarcinoma. Annu Rev Med 1987; 38:477-492.

44 Bersentes K, Fass R, Padda S, Johnson C, Sampliner RE: Prevalence of Barrett's esophagus in Hispanics is similar to Caucasians. Dig Dis Sci 1998;43:1038-1041.

-45 Shaheen N, Ransohoff DF: Gastroesophageal reflux, Barrett esophagus, and esophageal cancer: clinical applications. JAMA 2002; 287:1982-1986.

46 Shaheen NJ, Crosby MA, Bozymski EM, Sandler RS: Is there publication bias in the reporting of cancer risk in Barrett's esophagus? Gastroenterology 2000;119:333-338.
47 Chan MF: Complications of upper gastrointestinal endoscopy. Gastrointest Endosc Clin N Am 1996;6:287-303.

48 Froehlich F, Gonvers JJ, Vader JP, Dubois RW, Burnand B: Appropriateness of gastrointestinal endoscopy: risk of complications. Endoscopy 1999;31:684-686.

49 Galmiche JP: Treat or investigate? Eur J Gastroenterol Hepatol 1999;11(suppl 1):S11S15.

50 Vela MF: Empiric PPI therapy or endoscopy for the initial management of patients with GERD in the absence of alarm features? Nat Clin Pract Gastroenterol Hepatol 2008;5 548-549.

51 Pace F, Tonini M, Pallotta S, Molteni P, Porro GB: Systematic review: maintenance treatment of gastro-oesophageal reflux disease with proton pump inhibitors taken 'on-demand'. Aliment Pharmacol Ther 2007;26: 195-204.

52 Meineche-Schmidt V, Juhl HH, Ostergaard JE, Luckow A, Hvenegaard A: Costs and efficacy of three different esomeprazole treatment strategies for long-term management of gastro-oesophageal reflux symptoms in primary care. Aliment Pharmacol Ther 2004;19:907-915.
53 Caro JJ, Salas M, Ward A: Healing and relapse rates in gastroesophageal reflux disease treated with the newer proton-pump inhibitors lansoprazole, rabeprazole, and pantoprazole compared with omeprazole, ranitidine, and placebo: evidence from randomized clinical trials. Clin Ther 2001;23: 998-1017.

54 Galmiche JP: Non-erosive reflux disease and atypical gastro-oesophageal reflux disease manifestations: treatment results. Drugs 2006;66:7-13

55 Giannini EG, Zentilin P, Dulbecco P, Vigneri S, Scarlata P, Savarino V: Management strategy for patients with gastroesophageal reflux disease: a comparison between empirical treatment with esomeprazole and endoscopy-oriented treatment. Am J Gastroenterol 2008;103:267-275.

-56 Sarkar M, Hennessy S, Yang YX: Protonpump inhibitor use and the risk for community-acquired pneumonia. Ann Intern Med 2008;149:391-398.

57 Laheij RJ, Sturkenboom MC, Hassing RJ, Dieleman J, Stricker BH, Jansen JB: Risk of community-acquired pneumonia and use of gastric acid-suppressive drugs. JAMA 2004; 292:1955-1960. 